\title{
LA EXCEPCIÓN A LA COSA JUZGADA EN MATERIA PENAL CUANDO SE TRATA DE INDEMNIZACIONES CIVILES
}

\section{Leonardo Coronel Larrea}

Universidad San Francisco de Quito USFQ, estudiante del Colegio de Jurisprudencia, Campus Cumbayá, Casilla Postal 17-1200-841, Quito 170901, Ecuador.

Correo electrónico: leonardocoronellarrea@hotmail.com / lcoronel@estud.usfq.edu.ec

\section{Anabela Chiriboga Bucheli}

Universidad San Francisco de Quito USFQ, estudiante del Colegio de Jurisprudencia, Campus Cumbayá, Casilla Postal 17-1200-841, Quito 170901, Ecuador.

Correo electrónico: anabela_ch2107@hotmail.com / achiriboga@estud.usfq.edu.ec

Recibido / Received: 26/02/2019

Aceptado / Accepted: 26/03/2019

DOI: $10.18272 /$ lr.v6i1.1377

\section{Citación}

Coronel, L. S., y A. N. Chiriboga. «La excepción a La Cosa Juzgada En Materia Penal Cuando Se Trata De Indemnizaciones Civiles». USFQ Law Review, Vol. 6, n. ${ }^{o}$ 1, agosto de 2019, p. 23 , doi:10.18272/lr.v6i1.1377. 


\title{
RESUMEN
}

Dentro del ordenamiento jurídico ecuatoriano, se evidencia la extensión de facultades de los jueces penales, sobre la base del principio de reparación integral, para otorgar indemnizaciones civiles. En este sentido, existen inconvenientes cuando estos dańos, supuestamente resarcidos, carecen de efectividad, metodología o forma correcta de cuantificación. De tal forma, la víctima queda indefensa con una errónea restitución, y aparece el problema de la cosa juzgada en sentencias penales que no cumplen su finalidad resarcitoria. Por lo tanto, es necesario buscar una solución a la problemática planteada, toda vez que la víctima no tiene por qué soportar dańos que no los ha merecido, y mucho menos soportar indemnizaciones incorrectas. Para ello se analizará la institución de la res judicata y la posibilidad de dejar sin efectos sus características de inmutabilidad y definitividad. Además del aporte con otras formas de excepciones frente a la misma problemática, como son la prejudicialidad y la litispendencia.

\section{Palabras clave}

responsabilidad civil; responsabilidad penal; reparación integral; prórroga de competencias; indemnización; cuantificación; cosa juzgada; partes procesales; objeto; fundamento; prejudicialidad; litispendencia

\section{The Exception to The Res Judicata in Criminal Matters when It Comes to Civil Indemnities}

\begin{abstract}
Within the Ecuadorian legal system, there is evidence of the extension of the powers of criminal judges, based on the principle of integral reparation to grant civil indemnities. In this sense, there are disadvantages when these damages, supposedly compensated, lack effectiveness, methodology or correct form of quantification. Thus, the victim is left defenseless with an erroneous restitution, and the problem of res judicata appears in criminal sentences that do not fulfill their compensatory purpose. Therefore, it is necessary for this work to seek a solution to the problems raised, since the victim does not have to endure damages that he has not deserved, let alone bear incorrect compensation. To do this, the institution of res judicata and the possibility of leaving its immutability and definitive characteristics without effect will be analyzed. In addition to the contribution with other forms of exceptions to the same problem, such as prejudiciality and lis pendens.
\end{abstract}

\section{KEYWORDS}

civil liability, criminal liability, comprehensive reparation, extension of powers, compensation, quantification, res judicata, procedural parts, object, prejudicial, basis, lis pendens. 


\section{INTRODUCCIÓN}

El término responsabilidad a lo largo de la historia ha ido evolucionando en su contexto según la época que lo analizaba. Con el pasar del tiempo, se han podido evidenciar las distintas posturas que la doctrina ha creado a partir del daño, la indemnización y su fuente obligacional. Esto conlleva el análisis histórico de la responsabilidad y su visión en diferentes momentos, que inicia con la evolución del derecho de responsabilidad por daños, para, con posterioridad, aterrizar en el derecho ecuatoriano. En este último, se encajará un análisis profundo del modo en el que se percibía a la responsabilidad de manera general, con una analogía del sistema actual.

De esta manera, se podrán evidenciar los rezagos de un sistema jurídico ya derogado, pero que, sin duda alguna, se lo evidencia en la actualidad por una confusión entre la responsabilidad civil y penal. Sin embargo, tras ser analizados, se podrá verificar su total independencia y diferenciación, toda vez que su fundamento o fuente es distinta, así como su objeto y finalidad.

Debido a la nueva legislación penal, es decir la publicación del Código Orgánico Integral Penal (en adelante COIP), han aparecido nuevos retos y problemas jurídicos con respecto al Derecho de Responsabilidad por Daños. Estos se pueden evidenciar si son analizados de la mano del principio de reparación integral, consagrado, tanto en la Constitución como en el COIP. Ya que este principio es la fuente para la existencia de una prórroga de competencias civiles que recaen sobre el juez penal, cuando este considere acorde otorgar indemnizaciones civiles para resarcir el daño sufrido por la víctima del delito penal.

El problema en cuestión no es la extensión de competencias, o la extensión de facultades que recibe el juez penal, sino cómo este desarrolla y ejecuta estas funciones con respecto a la reparación del daño sufrido por la víctima. Es decir, se evidencia una ausencia de estructura y conocimiento con respecto a la correcta cuantificación de daños. Por lo que la solución que se plantea es la posibilidad de acceder a la vía civil, una vez establecido el cálculo en sede penal, debido a que la apreciación del juez penal, en varios casos, es errónea o sin método aplicable ya que se busca que el daño, nada más que el daño, sea resarcido.

Por lo tanto, este trabajo tratará de abordar la posibilidad de recurrir a la instancia civil y destruir los efectos de cosa juzgada en materia penal. Con el objetivo de que el agraviado pueda acceder bajo toda circunstancia a la finalidad que, como víctima, busca, es decir una indemnización correcta que aborde todos los perjuicios y menoscabos sufridos.

Finalmente se propondrá otras excepciones que, para efectos prácticos, pueden ser analizadas, para evitar que aquellas se interpongan frente al afán de la víctima de ser indemnizada en legal y debida forma. 


\section{Algunos anteCedentes}

Se hará un recuento del contexto histórico y se tratará de abordar todas las aristas posibles frente al problema jurídico planteado. Por lo tanto, es preciso esclarecer cada término que se emplea dentro del documento. De esta manera, el primer término por aclarar es responsabilidad. En el lenguaje filosófico, esta palabra abarca la posibilidad de preguntarle a otro obligándole a responder con explicaciones y también a conceder una satisfacción. López Olaciregui expresa que la "[r]esponsabilidad se compone de tres supuestos: (i) Un acto de un individuo, (ii) Un deber, (iii) Una infracción" ${ }^{1}$. En cambio, para Atilio Alterini el fondo y el sentido que se le debe otorgar a la palabra responsabilidad se limita a la reparación que deriva de una sanción ${ }^{2}$.

Este término ha ido evolucionando a lo largo del tiempo; sin embargo, sus primeros rasgos aparecen dentro del Derecho Romano. Este es la fuente del nacimiento de la responsabilidad. Sin embargo, no se podía hablar de un principio general de responsabilidad, debido a que el derecho de aquella época no estaba familiarizado con el término obligatio, más bien, se centraba en la palabra nexum, cuyo significado es ligar o anudar ${ }^{3}$. Este vínculo poseía un carácter material, se encontraba establecido por la Ley de las XII Tablas, donde decía que el deudor que no cumplía con lo que debía, podía ser tomado por el acreedor para que responda por su deuda con su propio cuerpo ${ }^{4}$.

Por lo tanto, se puede concluir que, en la Roma primitiva, no existía la diferenciación entre responsabilidad civil y penal, tampoco se evidenciaba nada respecto a otros pueblos primitivos que existían. Lo que primaba en ese tiempo era la venganza privada y reparar el daño mediante la Ley del Talión, que se fundamenta en el: "[o]jo por ojo, diente por diente", ya que la venganza o autotutela es considerada el primer mecanismo de composición del conflicto generado por el cometimiento de un dańo.

En dicha época existían dos categorías de daños. La primera se refiere a aquellos que nacían de un delito público y los que provenían de uno privado ${ }^{5}$. Esta división se produce debido a la lex aquilia. Sylvia Sack Ramos manifiesta que:

Por la crimina publica, el hecho dañino podía ser perseguido por cualquier miembro de la comunidad, dado su carácter público; en cambio, en los delitos privados, solamente los afectados podían perseguir el acto pernicioso, en cuyo caso la pena consistía en un resarcimiento económico. Sin embargo, el autor del ilícito no

\footnotetext{
López, Olaciregui, José María. Lecciones de Derecho Civil, parte segunda, volumen II, La responsabilidad civil. Buenos Aires: Zavalía, 1989, p. 68.

2 Alterini, Atilio. Temas de responsabilidad civil: contractual y extracontractual. Buenos Aires: Astrea, 1995, p. 550.

3 Morel, Juan. Responsabilidad civil a través de la Historia. Buenos Aires: Tiempo, 1997, p. 12.

4 Ibid.

5 Sack Ramos, Sylvia Jacqueline. "Responsabilidad civil en el nuevo proceso penal". Revista. (2015), p. 21.
} 
quedaba sometido meramente a una sanción pecuniaria, pues para él nace la obligación de pagar una suma de dinero, de satisfacer un crédito equivalente al valor de la cosa destruida; es decir, nace la idea de la obligación proveniente del delito ${ }^{6}$.

Es necesario mencionar la importancia del corpus iuris civilis, donde se presenció la modificación del sistema de la lex aquilia, ya que en su aspecto objetivo se extendió el concepto de daño material, mientras que, en el aspecto subjetivo consideraba que el hecho dańoso no era aceptado como punible cuando estaba exento de culpa o dolo ${ }^{7}$. Finalmente, se ampliaron los supuestos de las personas que podían ejercer esta acción.

Mediante la actio legis aquiliate, había la posibilidad de solicitar la indemnización de un daño o un perjuicio sufrido comprendiendo el dańo emergente y el lucro cesante, a tal punto que, como expresa Peirano: “[l]a acción [...] perdió más y más su carácter penal hasta el punto de presentar al final de la evolución el Derecho Romano el carácter de una acción no penal, destinada principalmente a obtener la reparación del daño acarreado por el hecho" ${ }^{8}$.

Con respecto al Derecho Francés, se evidencia un progreso de suma importancia. En este se comienza a observar por primera vez la separación de la responsabilidad civil de la penal con la creación del Ministerio Público, a través de la Ordenanza del 25 de marzo de $1302^{9}$. Sin embargo, es necesario hacer referencia que la distinción entre ambas instituciones no fue absoluta, ya que la acción que se le confirió a la víctima nunca dejo de mantener en algo su origen de carácter penal, más que nada cuando se hablaba de un daño o perjuicio que afectara a la integridad o el honor de un individuo.

El deber más importante de este antiguo derecho no es solo el de haber creado una separación y distinción entre la responsabilidad civil y la penal, sino que además ofreció el inicio de un principio general de responsabilidad civil.

El Código Francés, o también conocido como el Código Napoleónico, es el antecedente moderno del régimen de resarcimiento de daños extracontractuales. Por un lado, en el artículo 1382 del código antes mencionado prescribe que el hecho intencional da lugar a la reparación ${ }^{10}$. Por otro lado, en su artículo 1383 dice que "[c] ada cual es responsable del daño que ha causado, no solo por su hecho, sino también por su negligencia o imprudencia" ${ }^{11}$.

6 Ibid.

7 Ortega Carrillo, Antonio. Derecho Privado Romano. Málaga: Ed. del Genal, 2010, p. 65.

8 Peirano Facio, Jorge. Responsabilidad extracontractual. Uruguay: Editorial 101, 2016, p. 114.

9 Mazeaud, Henri; Mazeaud, León; y Mazeaud, Jean. Lecciones de Derecho Civil. Buenos Aires: Ediciones Jurídicas EuropaAmérica, 1965, p. 361.

10 Código Civil de Napoleón (1804). Artículo 1382.

11 Eiusdem. 
La mayoría de los ordenamientos jurídicos continentales han utilizado de inspiración y ejemplo, tanto al Derecho Romano, como al Derecho Francés, por lo que son las fuentes primordiales del sistema que en la actualidad se acoge. Sin embargo, estos sistemas jurídicos han presenciado un cambio a partir de la evolución y avances que la humanidad ha creado.

Debido al notable desarrollo en las grandes industrias, los trabajadores se vieron sometidos a varios accidentes laborales, lo que dio paso a la llamada teoría del riesgo. Es ahí, donde por primera vez se habla no solo de una reparación por los daños que ha sufrido la víctima, también se hace referencia a una sanción a quien ha incurrido en ciertas faltas que vulneren el orden social. Posteriormente es la misma sociedad que va a ser quien corresponsabilizada de algún modo, da origen a lo que conocemos como teoría de la distribución social de daños, que al mismo tiempo incluyo un sistema de precios y también la contratación de seguros ${ }^{12}$.

Tras la década de los setenta, a partir de las teorías de la responsabilidad civil, fue creándose una teoría sobre el Derecho de daños, la cual ha provocado el desarrollo de principios básicos de la responsabilidad civil, como la culpa y el riesgo; atribuyéndosele la función de prevenir comportamientos antisociales, establecer indemnizaciones para las víctimas y garantizar los derechos de las personas. Acota el autor Gálvez Villegas que lo que se pretende con la reparación del daño, autónomamente del reproche o la culpa del agente, es modificar la responsabilidad civil, concediendo responsabilidad al causante del daño a través de factores objetivos de imputación, además de factores clásicos subjetivos, que vienen a ser la culpa y el dolo ${ }^{13}$.

\section{El antiguo derecho ECUATORIANo}

Tras la exposición de cómo ha ido evolucionando la responsabilidad a lo largo de la historia. Es necesario aterrizar en el anterior ordenamiento penal ecuatoriano, por su gran importancia e incidencia con respecto al Derecho de Responsabilidad por Daños civiles.

Este cuerpo normativo derogado evitaba el poder hacer una distinción entre las responsabilidades civil y penal. Por lo tanto, es menester hace referencia al artículo 41 del antiguo Código de Procedimiento Penal el cual prescribía:

Las sentencias ejecutoriadas en los procesos civiles no producen el efecto de cosa juzgada en lo penal, excepto las que deciden las cuestiones prejudiciales indicadas en el artículo anterior. Las sentencias ejecutoriadas en los procesos penales producen el

12 Roppo, Vicenzo; y Alpa, Guido. Responsabilidad civil. Lineas fundamentales y nuevas perspectivas. Lima: Juristas Editores, 2007, p. 49

13 Gálvez Villegas, Tomás Aladino. Responsabilidad civil extracontractual y delito. Lima: Universidad Nacional Mayor de San Marcos, 2008, p. 38. 
efecto de cosa juzgada, en lo concerniente al ejercicio de la acción civil, solo cuando declaran que no existe la infracción o, cuando existiendo, declaran que el procesado no es culpable de la misma. Por tanto, no podrá demandarse la indemnización civil derivada de la infracción penal mientras no exista una sentencia penal condenatoria ejecutoriada que declare a una persona responsable de la infracción ${ }^{14}$.

Lo antes mencionado se puede ratificar con la sentencia del caso "El Gran hermano", donde el economista Rafael Correa dedujo ante la Jueza Quinta de lo Civil una acción por daño moral en contra de los periodistas Juan Carlos Calderón Vivanco y Christian Gustavo Zurita Ron sobre la base de ciertas afirmaciones contenidas en la obra que le habrían provocado perjuicios extrapatrimoniales ${ }^{15}$. Es necesario mencionar que, por la forma en que se planteó la demanda, para que procediera la acción civil, era necesaria una condena penal previa, firme y ejecutoriada.

Los casos de prejudicialidad civil para el ejercicio posterior de la acción penal se encontraban taxativamente enumerados en la ley. La situación opuesta, esto se refiere, de lo penal a lo civil, opera en función de un principio genérico de admisibilidad. En efecto, estos últimos estaban basados en la necesidad que exista una sentencia penal condenatoria y ejecutoriada respecto de cualquier infracción penal previo al ejercicio de la acción civil de daños y perjuicios.

Si la Jueza, sobre la base de los hechos y fundamentos jurídicos que el actor alegó, encontró que las conductas de los demandados se encasillaban dentro de los tipos penales, era necesario que el juez de garantías penales resuelva la causa y determina la declaratoria de responsabilidad penal.

El artículo 2232, inciso segundo, del Código Civil del Ecuador expresa:

"[D] ejando a salvo la pena impuesta en los casos de delito o cuasidelito, están especialmente obligados a esta reparación [léase indemnización] quienes, en otros casos de los señalados en el artículo anterior, manchen la reputación ajena, mediante cualquier forma de difamación"16.

Ha de entenderse que quien era declarado culpable de un delito penal de injuria en sentencia condenatoria se encontraba obligado, junto a las indemnizaciones por dańos y perjuicios patrimoniales, a la indemnización por daño moral. Sin embargo, para el ejercicio de cualquiera acción civil, se requería, previamente, de la sentencia penal condenatoria ejecutoriada.

A partir de este análisis, se entiende que en Ecuador no se hacía una diferencia entre la responsabilidad civil y la responsabilidad penal, ya que, para fines, tanto

14 Código de Procedimiento Penal. Artículo 41. Registro Oficial No. 555 Suplemento de 24 de marzo de 2009.

15 Corte Suprema de Justicia. Sala de lo Civil y Mercantil de la ex Corte Suprema de Justicia. Caso 79-2003. Sentencia, 6 de febrero de 2009.

16 Código Civil. Artículo 2232. Registro Oficial No. 46 Suplemento de 22 de mayo de 2016. 
teóricos como prácticos, eran consideradas como iguales, además de ser producto de una misma fuente. Actualmente, el contenido descrito ha cambiado a partir de la publicación del COIP, cuerpo normativo que soluciona este inconveniente, pero genera otros con respecto a las indemnizaciones que el juez penal tiene la facultad de otorgar a la víctima.

\section{LA DISTINCIÓN ENTRE RESPONSABILIDAD CIVIL Y RESPONSABILIDAD PENAL}

Es importante analizar y aclarar cada término empleado dentro de la hipótesis planteada dentro de este trabajo. Para ello es importante utilizar las palabras de Guillermo Cabanellas que, en su Diccionario Jurídico Elemental, se refiere a la responsabilidad como "[1]a obligación de reparar y satisfacer por uno mismo o, en ocasiones especiales, por otro, la pérdida causada, el mal inferido o el daño originado"17.

En la obra Responsabilidad civil en el nuevo proceso penal, de Sylvia Sack Ramos, se encuentra el siguiente pensamiento:

En términos simples, la responsabilidad es el conjunto de consecuencias de una acción u omisión ilícitas, de las cuales derivan la obligación de satisfacer el daño o la pérdida causada. Responsabilidad también se denomina a la capacidad de un ser humano de discernir sus acciones a través de su voluntad razonada, de manera que pueda asumir el compromiso de sus acciones [...] en sentido jurídico responsabilidad puede definirse como la situación del sujeto al que le toca experimentar, concretamente las consecuencias, para él desventajosas que una norma prevé y le impone atendiendo a la verificación de un determinado presupuesto ${ }^{18}$.

La distinción entre responsabilidad civil y responsabilidad penal, según Francesco Carnelutti, son la pena y la restitución. La restitución tiene por objeto la cosa; la penitencia tiene por objeto al hombre. Bajo esta premisa el autor aclara la esfera donde se encuentra cada elemento: "La penitencia tiende a poner en su lugar las cosas; la pena, a poner de nuevo en su lugar al hombre"19. Por lo tanto, es evidente que existe una diferenciación entre responsabilidades desde cualquier óptica vista.

Por consiguiente, se puede afirmar que el ordenamiento jurídico distingue la responsabilidad civil y la responsabilidad penal de conformidad con las acciones $\mathrm{u}$ omisiones del ser humano, generando, en el caso de las primeras, una reparación del daño causado dentro de la esfera civil; y, en el caso de la segunda, enfrentando una pena determinada en la ley en la órbita penal.

17 Cabanellas de la Torres, Guillermo. Diccionario Juridico Elemental, Buenos Aires: Heliasta, 1982, p. 283.

18 Sack Ramos, Sylvia Jacqueline. Óp. cit., p. 27.

19 Carnelutti, Francesco. Derecho Procesal Civil y Penal. México: Harla, 1994, p. 35. 
La responsabilidad civil busca el resarcimiento de un dańo sea este patrimonial o extrapatrimonial y este se reduce a una cuestión económica. En cambio, al hablar de responsabilidad penal el tema central es la pena, que es la consecuencia de un acto u omisión ilícito, que debe ser típico, antijurídico y culpable, con la finalidad que el autor de la conducta soporte la sanción que le impone la ley.

Siguiendo la misma línea interpretativa, existen varias diferencias entre estos tipos de responsabilidades. Una de ellas radica en su carácter personalísimo, por cuanto la responsabilidad penal puede incidir únicamente sobre el infractor de la ley; por el contrario, la responsabilidad civil puede recaer sobre terceros, conocida como responsabilidad vicaria.

Otra de estas es que la responsabilidad penal no es transigible, ya que se trata de conductas que no respetan los derechos constitucionales reconocidos, ni los diferentes bienes jurídicos protegidos, debido a que vulneran y atacan el interés general. No puede el agraviado en ninguna circunstancia evitar o tratar de evitar que se apliquen las consecuencias previstas para quien ocasionó el daño, de manera que, no se puede transar, o dar paso a una negociación. Mientras que, si la responsabilidad civil es sujeto de estudio, se tendrá como consecuencia que esta materia y tipo de responsabilidad es transable, negociable, con la posibilidad y capacidad de llegar a un acuerdo, por ser eminentemente patrimonial” ${ }^{20}$.

Con respecto a la ausencia de responsabilidad, dentro de la responsabilidad penal, existen cinco formas en las que el hecho antijurídico deja de serlo. Son conocidos como causas de justificación y son: (i) la legítima defensa; (ii) el estado de necesidad justificante; (iii) el consentimiento de titular; (iv) la orden de autoridad; y, (v) el mandato de ley. Mientras que, en la responsabilidad civil los eximentes de responsabilidad son los siguientes: (i) el hecho realizado por un tercero; (ii) el caso fortuito o la fuerza mayor; y, (iii) la culpa exclusiva de la víctima.

En cuanto a la responsabilidad civil, podrían existir excepciones a este principio, sin afirmar que no se aplique en materia civil, toda vez que la culpabilidad se puede presumir en casos como: (i) el daño moral y la aplicación del in re ipsa mediante una prueba indiciaria del daño; (ii) las actividades peligrosas; (iii) hechos de terceros; y. iv) la responsabilidad subjetiva con inversión de la carga de la prueba ${ }^{21}$.

Finalmente, dentro de la responsabilidad penal no existen presunciones de culpabilidad, por la existencia del principio de presunción de inocencia, que cobija y favorece a quien se dice que cometió el ilícito que causó el daño. La Constitución de la República del Ecuador, en su artículo 76, numeral 2 prescribe: "Se presumirá la inocencia de toda persona, y será tratada como tal, mientras no se declare su

20 Martínez Rave, Gilberto. Responsabilidad civil extracontractual. Bogotá: Temis, 1998, p. 108.

21 Id.. p. 110. 
responsabilidad mediante resolución firme o sentencia ejecutoriada"22. Es el Estado quien tiene el deber de demostrar que el hecho en cuestión es punible para proceder a exigir la responsabilidad penal; de no lograrse lo antes mencionado, el autor tendrá que ser absuelto por la presunción de inocencia.

\section{EL PRINCIPIO DE REPARACIÓN INTEGRAL}

De acuerdo con la definición que da el Diccionario de la Real Academia, reparar es: "Desagraviar, satisfacer al ofendido, remediar o precaver un perjuicio o daño"23, mientras que la Corte Interamericana de Derechos Humanos manifiesta que "[l]a reparación es el término genérico que comprende las diferentes formas de garantizar al lesionado el goce de su derecho transgredido ${ }^{24}$.

La reparación integral, en términos generales, supone volver al estado de cosas anterior a la comisión del daño. En este sentido, el COIP se ocupa en varios artículos de la reparación a las víctimas bajo el presupuesto de que se ha declarado la culpabilidad del infractor, en cuyo caso el juzgador deberá disponer también la reparación integral a favor de la víctima y debe hacerlo de manera motivada, determinando el monto económico que la persona sentenciada debe pagar a favor del agraviado.

El artículo 52 del COIP prescribe, acerca de la finalidad de la pena del imputado, que la persona condenada está obligada a la reparación del daño de quien lo su$\mathrm{fre}^{25}$. De la misma manera, el art. 78 del código citado establece los mecanismos de reparación integral y, en su numeral 3, ordena las indemnizaciones de daños materiales e inmateriales que se refieren a la compensación por todo perjuicio que resulte como consecuencia de una infracción penal y que sea evaluable económicamente $^{26}$. En el mismo sentido, el artículo 619 contempla los requisitos de la decisión judicial y su numeral 4 de indica que, una vez declarada la culpabilidad y la pena, el juzgador dispondrá la reparación integral de la víctima siempre que esta sea identificable ${ }^{27}$.

Igualmente, el artículo 621 de este cuerpo normativo obliga a que esta incluya una motivación completa y suficiente en lo que tiene que ver con la responsabilidad penal, con la determinación de la pena y la reparación integral al agraviado. El artículo 622 regula los requisitos de la sentencia y, en su numeral 6, indica que se debe considerar como uno de los requisitos la condena por la infracción que ocasionó los daños que se van a reparar integralmente con la determinación del

22 Constitución de la República del Ecuador. Artículo 76.2. Registro Oficial No. 449 de 20 de octubre de 2008.

23 Real Academia Española. (2014). Diccionario de la lengua española (24. ${ }^{a}$ ed.). Madrid: Real Academia Espańola.

24 Rojas Nash, Claudio. Las reparaciones ante la Corte Interamericana de Derechos Humanos. Chile: Andros Impresores, 2007, p. 102.

25 Código Orgánico Integral Penal. Artículo 52. Registro Oficial No. 180 Suplemento de 21 de julio de 2016.

26 Rojas Nash, Claudio, Op. cit. p. 28.

27 Id., p. 166. 
monto económico que pagará la persona sentenciada a la víctima y demás mecanismos necesarios para la reparación integral ${ }^{28}$. Finalmente, el artículo 628 prescribe las reglas sobre la reparación integral en la sentencia, disponiendo que toda sentencia condenatoria deberá contemplar la reparación integral de la víctima ${ }^{29}$.

La Constitución de la República del Ecuador, al establecer la protección a las víctimas en el artículo 78, dispone que se adoptarán mecanismos para la reparación integral y que esta incluirá, sin dilaciones, el conocimiento de la verdad de los hechos y la restitución, indemnización, rehabilitación, garantía de no repetición y satisfacción del derecho que se ha vulnerado ${ }^{30}$. De esta norma constitucional se puede deducir que la reparación integral debe ser eficaz, rápida y eficiente.

La reparación integral alcanza caracteres de suma importancia en la legislación ecuatoriana, en especial la materia penal. El COIP, en su artículo 78, prescribe los mecanismos de reparación integral indicando que son los siguientes: (i) la restitución; (ii) la rehabilitación; (iii) las indemnizaciones de daños materiales e inmateriales; (iv) las medidas de satisfacción o simbólicas; y, (v) las garantías de no repetición (énfasis añadido) ${ }^{31}$.

Llevando a cabo un análisis de la ley vigente (COIP), se puede notar un cambio de la justicia, al dar mayor participación a las víctimas por una infracción penal, siendo necesario en las decisiones de quienes administran justicia la reparación para el agraviado. José Luis de los Mozos, en su obra Responsabilidad civil de Derecho de daños, plantea que, "[c]uando se alude al concepto indemnización se entiende de manera implícita que para ser tal debe cubrir el daño resarcible en su totalidad; de no ser el caso, no es una indemnización, más bien, sería considerado como un paliativo dinerario, una ayuda" 32 .

En resumen, las víctimas gozan de plenos derechos recogidos por la ley del Ecuador, de manera que se garantiza el pronto acceso a la justicia, al mismo tiempo indica que tienen el derecho a la verdad y a formar parte activa durante el proceso penal.

La reparación integral como concepto es relativamente nuevo en el universo del Derecho ecuatoriano. La Carta Magna registra el derecho a la reparación integral como parte de un modelo de justicia nuevo, que busca no solo reconocer, sino también garantizar el derecho de los agraviados que han sufrido por agresiones penales a que lleguen a ser reparados de forma integral por los daños o perjuicios que se les haya ocasionado a razón del cometimiento de un ilícito.

28 Id., p. 167

29 Id., p. 168

30 Constitución de la República del Ecuador. Eiusdem, artículo 78.

31 Código Orgánico Integral Penal. Eiusdem, artículo 78.

32 De los Mozos, José Luis. Responsabilidad civil. Derecho de daños. Perú: Jurídica Grijley, 2006, p.227. 
De todo lo mencionado, se puede deducir que la reparación integral para el sentenciado constituye una forma en la que se resarcen los dańos ocasionados, sin perjuicio de la pena que las leyes establezcan para el delito causante del daño. Con respecto a la víctima, es un derecho que está garantizado tanto en la normativa constitucional, como en la ley penal ecuatoriana y busca la restitución del daño al momento anterior que ocurra. A partir de las normas citadas, no cabe duda de que el juez penal tiene facultades para otorgar indemnizaciones civiles dentro de sus resoluciones penales, por lo que se evidencia una prórroga de competencias en sus funciones, que podrían generar problemas fácticos y jurídicos con respecto a la correcta tasación de daños.

\section{Sobre LA PRÓRRoga DE COMPETENCIA}

El término competencia proviene de competer, que significa corresponder, incumbir a alguien una cosa, es decir, la medida en que la jurisdicción es distribuida entre las diferentes autoridades jurisdiccionales ${ }^{33}$. Se sostiene entonces que, la competencia es aquel limite que se le impone a la jurisdicción. En palabras de Mattirolo, "[e]s la medida como se distribuye la jurisdicción entre las autoridades que [la] ejercen [...]. Es la parte de poder jurisdiccional [que posee] [...] cada juez o magistrado; [en su propia] medida" ${ }^{34}$.

Se puede decir que la competencia es la aptitud legal para poder ejercer jurisdicción en un determinado proceso. Es menester recalcar que todos los jueces poseen jurisdicción, ya que son los representantes directos de la función jurisdiccional. Esta facultad puede ser puesta en práctica únicamente dentro de los límites que la competencia permitida legalmente. Al respecto, Teresa Armenta Deu sostiene que "[l]a competencia es el límite de la jurisdicción, razón lógica para que no todos los jueces tengan la misma competencia. Si el juez conociera de toda clase de asuntos desembocaría en un verdadero caos jurídico" 35 .

En cuanto a la prórroga de la competencia, esta procede solamente respecto al elemento territorio. Al referirnos a los elementos materia, fuero y cuantía, existe un carácter normativo y no son susceptibles de prorrogación. El artículo 162, inciso 5 del Código Orgánico de la Función Judicial expresa que "[e]n ningún caso se prorroga la competencia en razón de la materia"36.

Existen dos posturas al respecto. Por un lado, se encuentra la hipótesis guiada por el Código Orgánico de la Función Judicial, en la que no es aplicable en Ecuador la prórroga de competencias con respecto a la materia, según el artículo anteriormente citado. Por otro lado, existe la tesis que sostiene que, en el proceso penal,

33 Torrent, Armando. Manual de Derecho Privado Romano. Zaragoza: Liberia Central, 1987, p. 50.

34 Mattirolo, Luis. Tratado de Derecho Judicial Civil. Madrid: Reus, 1934, p. 115.

35 Armenta Deu, Teresa. Lecciones de Derecho Procesal Civil. Madrid: Ediciones Jurídicas y Sociales, 2015, p. 63.

36 Código Orgánico de la Función Judicial. Artículo 162. Registro Oficial No. 544 Suplemento 544 de 22 de mayo de 2015. 
el juez tiene la posibilidad de prorrogar sus competencias para conceder la indemnización civil de daños y perjuicios a la víctima, una vez que se ha determinado la comisión de un delito. Bajo este presupuesto, es necesario recordar las normas establecidas en el COIP, con respecto a la indemnización de la víctima sobre la base del principio de reparación integral [Supra $\$ 4]$.

Por lo tanto, la extensión de competencias que concierne al presente análisis "constituye una excepción [...], que permite desplazar la competencia de un juez a otro para conocer [...] un asunto litigioso" ${ }^{\prime 3}$. Ello en virtud que la teoría penal moderna contempla la reparación integral de los dańos causados por el cometimiento de un delito ${ }^{38}$. De esta manera, se evidencia la posibilidad existente en el ordenamiento jurídico ecuatoriano, de analizar esta extensión de competencias con el fin de dar una solución a la interrogante planteada.

\section{El NÚCLEO DEL PROBLEMA. LA INCONFORMIDAD DE LA INDEMNIZACIÓN PENAL}

En este momento todos los conceptos analizados anteriormente convergen y forman la duda planteada en un inicio. En efecto, una conducta ilícita que se juzga en el ámbito penal puede producir un resultado indemnizable de carácter civil. Por un lado, estas pueden traducirse como una afectación extrapatrimonial en contra de una persona, o como el COIP las recoge, un daño inmaterial. Por otro lado, también puede darse un perjuicio patrimonial en cuyo caso la indemnización se compone del lucro cesante y daño emergente, o daños materiales según la misma legislación penal. Por lo tanto. es evidente que, en estos casos, la responsabilidad civil nace desde una infracción que afecta negativamente un bien jurídico protegido $y$, por tal, el juez penal tiene el deber de buscar la reparación de la víctima en todo sentido y aspecto. Esto se refleja en dos ámbitos distintos que no deben ser fusionados, toda vez que ha quedado claro que el cumplimiento de la pena impuesta es totalmente distinto a la restitución que busca toda indemnización civil.

Ahora bien, una vez establecida las facultades del juez penal con respecto a temas civiles, con el propósito de no dejar indefenso a quien fue afectado en un bien jurídico y en su patrimonio, a simple vista no existiría problema alguno. Sin embargo, el problema aparece cuando estas indemnizaciones no cumplen con el deber primordial que es el resarcimiento de la víctima, sea por errónea o falta tasación del dańo. Al respecto se ha pronunciado Jesús Silva al manifestar que esta forma de resolución no funciona; sin embargo, se la sigue utilizando por economía procesal, para evitar una peregrinación entre materias dentro del sistema jurisdiccional ${ }^{39}$.

37 Alvarado Velloso, Adolfo. Introducción al estudio del Derecho Procesal. Argentina: Rubinzal-Culzoni, 1969, p.43.

38 López Barajas, Inmaculada. "Garantías constitucionales en la investigación tecnológica del delito: Previsión legal y calidad de la Ley”. Revista de Derecho Politico (2017), p. 15.

39 Silva Sánchez, Jesús María. Aspectos de la llamada "responsabilidad civil" en el proceso penal. Barcelona: Universitat Pompeu Fabra, 2001, p.completar. 
$\mathrm{Al}$ ser considerado el Derecho Penal como una materia de ultima ratio en la que no debe existir duda alguna para utilizarla, el juez penal se ve en una encrucijada el momento de verificar los requisitos del delito y a la vez cuantificar los dańos sufridos por la víctima. Dado que, todos estos aspectos deben ser enunciados y analizados el momento de dar la resolución del proceso. Además, la dificultad trasciende a esferas superiores cuando el juez dicta una indemnización sin analizar si quiera los dańos, ya que no existe momento procesal alguno para hacerlo. Es por esta razón que Santiago Andrade Ubidia realiza una crítica al sistema y menciona que el juez debe analizar los daños para poder indemnizar de manera correcta, porque si no siempre existirán problemas con respecto a su tasación ${ }^{40}$. Por lo tanto, es totalmente contraproducente que el juez falle a ciegas, además de la ausencia de un método práctico de cuantificación que debe ser sustentado y motivado, por lo que los criterios deberían ser unánimes y vinculantes. Frente a esto, se evidencian los múltiples problemas que en pro de la economía procesal han ocurrido.

En este sentido se debe aclarar y establecer las dos formas en las que se puede obtener una indemnización civil dentro de un procedimiento penal, siempre como fundamento el principio de reparación integral consagrado en la Constitución y el COIP. La primera forma es mediante acusación particular de la víctima, este derecho está recogido en el art. 18 del COIP, que prescribe que la víctima tiene la opción de intervenir en el proceso mediante una acusación particular a su arbitrio $^{41}$. De tal forma, el artículo 432 y posteriores del mismo cuerpo normativo, regulan su forma de presentación y efectos para fines de legalidad.

Dentro de una acusación particular, el fin último es que la víctima pueda ser resarcida, por lo que, en principio, esta renunciaría a la acción de daños en vía civil.

La segunda hipótesis en la que una víctima del ilícito penal puede recibir una indemnización en sentencia, se fundamenta en el art. 432 en su numeral 1 del COIP que prescribe que la víctima podrá ser resarcida, "por sí misma o a través de su representante legal, sin perjuicio de intervenir en todas las audiencias y de reclamar su derecho a la reparación integral, incluso cuando no presente acusación particular" (énfasis añadido) ${ }^{42}$. Es decir, a pesar de no ser acusador particular, la víctima puede ser indemnizada por los daños sufridos, ya que no es necesaria esta configuración, sino solo la identificación, correcta tasación del daño ocurrido.

El problema radica el momento en el que los jueces deben aplicar estas facultades que la ley otorga, toda vez que se han mencionado las dificultades con respecto al ejercicio de estas competencias. Si bien los jueces han utilizado sus funciones, es preciso analizar cómo han fallado con respecto a la reparación integral de la víctima para, de esta forma, llegar a una conclusión con respecto de las opciones

40 Ubidia Andrade, Santiago. La indemnización de daños y perjuicios en la sentencia penal. Cuenca: Universidad del Azuay, 2012, p. 45.

41 Código Orgánico Integral Penal. Eiusdem, artículo 18.

42 Ubidia Andrade, Santiago. Op. cit., p. 109. 
del agraviado que no ha sido satisfecho en sus pretensiones o indemnizaciones con respecto al daño sufrido.

En el caso 1002-2013SP, la Sala de lo Penal de la Corte Nacional de Justicia, tras el análisis respecto de un delito de violación, supo manifestar dentro de la decisión que "[s]e dispone reparación integral de la víctima” ${ }^{3}$. Este es el tenor literal que el tribunal utilizó para referirse al resarcimiento de daños que sufrió la víctima. En estos casos, existe la duda de cuáles son los mecanismos y como se debe indemnizar al agraviado. Además, si estas son reparaciones monetarias, no cuantificables o simplemente es un deber formal que se topa para cumplir con lo dispuesto en la ley.

De la misma manera, en el caso 147-2011 la Sala especializada en lo Penal se pronunció con respecto a un caso de robo, en el que se resolvió dar el monto de doscientos dólares de los Estados Unidos de América $(200,00)$ a la víctima, sobre la base del principio constitucional de la reparación integral ${ }^{44}$. Este monto representaba lo perdido por el agraviado el momento del suceso, es decir una cuantificación solamente del daño emergente sufrido.

Tomando en cuenta ambos casos, se concluye que los jueces penales, en ciertos casos, no resarcen los daños que la víctima en realidad sufrió, a tal punto de solo pronunciarse declarando el derecho vulnerado y su respectiva necesidad de reparación, pero olvidándose del método de restitución. Por el contrario, existen casos en los que el juez identifica el daño material y la forma en la que se deben restituir, pero olvida el inmaterial o extrapatrimonial, que la víctima pudo haber pasado el momento en el que se perpetró el ilícito penal.

Asimismo, en el Juicio Penal 103-2015, dentro de un recurso de casación en el que la Corte Nacional de Justicia analizó un caso de asesinato, donde se ratificó la sentencia de la Corte Provincial de Pichincha, se podría desprender lo siguiente: "[A]tendiendo lo dispuesto por el artículo 78 de la Constitución de la República, como indemnización de daños y perjuicios deberá pagar al acusador particular la suma de doscientos mil dólares de los Estados Unidos" 45 . Sin embargo, no existía un análisis adecuado de la cuantificación del daño, pues es irrisorio que esta suma se refiera estrictamente al valor de la vida de la víctima, hablando de un daño inmaterial, o de lo que la víctima ganaba por su desarrollo profesional, hablando de dańos materiales. Nuevamente se evidencia la falta de una motivación o justificación de la indemnización, y a qué daño específicamente se refiere, si se habla estrictamente de daños patrimoniales o se ingresa en la esfera de daños extrapatrimoniales.

43 Corte Nacional de Justicia. Sala de lo Penal. Causa No. 1002-2013SP, Sentencia, 22 de noviembre de 2013.

44 Corte Nacional de Justicia. Sala de lo Penal. Causa No. 147-2011, Sentencia, 18 de enero de 2013.

45 Corte Nacional de Justicia. Sala Especializada de lo Penal, Penal Militar, Penal Policial y Tránsito. Causa No. 103-2015, Sentencia, 23 de noviembre de 2015. 
La pregunta que aparece en estos momentos es ¿qué puede hacer la víctima frente a una indemnización incompleta o deficiente? Por esta razón, con anterioridad, se había mencionado que, si prima facie, se utilizaba el mecanismo penal para resarcir daños, se perdía la instancia civil. Sin embargo, en ciertos casos es totalmente válido que el agraviado inicie una acción civil en busca del resarcimiento si los daños no fueron cuantificados o tasados de manera correcta, para evitar que la víctima no sufra un menoscabo que no tenía por qué padecer.

\section{La cosa JUZGada}

Para Hernando Devis Echandía, la cosa juzgada es una institución contenida en la ley que sirve para expresar la voluntad del Estado frente a la inmutabilidad de los casos resueltos y declarados en sentencia por medio de los jueces que forman parte de la función jurisdiccional ${ }^{46}$. Esto trae como consecuencia el establecimiento de una "verdad" que debe ser respetada y acogida por todos como tal. En palabras de Enrique Falcón, esta irrevocabilidad e inmutabilidad no puede ser alterada en procesos posteriores, por lo que de estar acompañada del principio non bis in idem, para que todo reclamo posterior sea inadmisible cuando se pretenda discutir de lo ya decidido ${ }^{47}$.

A simple análisis, resulta comprensible y sin dificultades la lectura de esta institución, sin embargo, las cosas se complican cuando se evidencia el pensamiento propuesto por Gozaini: ¿el contenido de verdad es totalmente perenne o existe algo con carácter definitivo? ${ }^{48}$.

Esta pregunta lleva el análisis a un escalón superior, y es el análisis correcto con respecto al caso planteado. Mediante esta incógnita se pretende que la víctima que no fue resarcida de manera adecuada pueda utilizar la vía civil para que exista una correcta cuantificación y por ende indemnización de daños. Como consecuencia de este accionar, se verán contradichos el principio de economía procesal jurisdiccional, la paz social resultante de la sentencia, y el efecto de seguridad jurídica que cobija a toda resolución con el carácter de cosa juzgada.

Para ello es imprescindible analizar la naturaleza de la res judicata. $\mathrm{Al}$ respecto, se pueden identificar dos posturas: aquellos que defienden y sostienen la teoría sustancialista de la cosa juzgada y la teoría procesal de la cosa juzgada ${ }^{49}$. En este sentido, la primera se fundamenta en que la cosa juzgada es de carácter sustantivo, debido a que crea, modifica o extingue relaciones jurídicas previas. Utilizando las palabras de Allorio, esta aptitud representa una novación del vínculo preexistente, por lo que sería evidente la extinción del derecho litigioso posterior ${ }^{50}$.

\footnotetext{
46 Echandía Devis, Hernando. Teoría General del Proceso. Bogotá: Temis, 2017, p. 440.

47 Falcón, Enrique. Tratado de Derecho Procesal Civil, Comercial y de Familia, Tomo III. Buenos Aires: Rubinzal-Culzoni, 2006, p. 671.

48 Gozaini, Oswaldo. Tratado de Derecho Procesal Civil. Buenos Aires: La Ley, 2009, p. 860.

49 Id., p. 863

50 Allorio, Enrico. Problemas de Derecho Procesal, Tomo II. México: Ediciones Jurídicas Europa-América, 1963, p. 131
} 
En contraposición, Goldschmidt afirma que los efectos que yacen en la cosa juzgada son exclusivamente procesales y se activan cuando se verifica la sentencia, sin importar los efectos materiales o sustantivos que tenga ${ }^{51}$.

Al respecto se acoge la postura emitida por Devis Echandía, quien afirma que la naturaleza de la cosa juzgada "es estrictamente procesal porque es una consecuencia del proceso y la emanación de voluntad del Estado manifestado en la ley procesal ${ }^{52}$. La razón radica en el argumento mismo, debido a que solo se trata de un efecto netamente procesal facultado por la ley, mas no ante una hipótesis sustantiva.

Además, que la cosa juzgada no es perenne ni absoluta. Ya que es evidente que en ciertos casos tendrá que prevalecer la realidad, antes que la presunción de verdad contenida en esta institución jurídica. En este sentido, el fundamento que se busca es aquel que representa un contenido pleno y absoluto, en el que no quepa duda de que la maquinaria judicial resolvió el conflicto sobre la base de los antecedentes de cognición y el razonamiento del juez ${ }^{53}$.

Si este presupuesto no es posible, o no se configura, "la revisión de la cosa juzgada es una probabilidad que refuerza el valor humano del proceso y muestra las debilidades del sistema que gobierna la temática como una exclusiva situación procesal" 54 . Es decir, si no se cumple la condición básica para la inmutabilidad de la sentencia, que es la certeza de los hechos controvertidos para que lleguen a ser absolutos, lo que trae como consecuencia que el asunto litigioso puede ser editado y planteado de nueva manera y forma.

\subsection{LOS LÍMITES DE LA RES JUDICATA}

Los límites de la cosa juzgada buscan esclarecer hasta que punto la cosa juzgada es aplicable ${ }^{55}$ y mantiene su carácter de inmutabilidad frente a nuevos procesos en contra de sentencias con este carácter. La doctrina ha determinado que existen dos límites, el subjetivo en razón de las personas que han sido partes del proceso y el objetivo por razón del objeto o cosa sobre el que versó el litigio y la causa en la que se fundó el reclamo ${ }^{56}$. Estos límites se verán analizados por el juez, cuando se pretenda fundar un nuevo proceso, frente a uno con el carácter de cosa juzgada. Es ahí el momento preciso en el que el juez debe realizar el siguiente análisis:

El juez [...] debe partir de un análisis del propósito del legislador al establecer la cosa juzgada [...]. La comparación entre esta y la nueva acción instaurada, el cotejo de sus elementos y la posible coincidencia entre ellos, es cuestión de lógi-

51 Goldschmidt, James. Derecho Procesal Civil. Madrid: Marcial Pons / Ediciones Jurídicas y Sociales, 2010, p. 388.

52 Echandía Devis, Hernando. Op. cit., p. 445.

53 Guillén, Fairén. La teoría del Derecho Procesal. México: Instituto de Investigaciones Jurídicas, 1992, p. 56.

54 Gozaini, Oswaldo. Op. cit., p. 871.

55 Falcón, Enrique. Op. cit., pp. 681, 682.

56 Echandía Devis, Hernando. Óp. cit., p. 449. 
ca y buen sentido, apoyado por las reglas generales de la hermenéutica jurídica. Finalmente, en crisis la cuestión de las tres identidades famosas, todo se reduce a analizar si podría o no haber escándalo derivado de fallos contradictorios, dictados por magistrados igualmente probos y capaces ${ }^{57}$.

En primer lugar, es menester realizar el análisis correspondiente con respecto al elemento subjetivo de la cosa juzgada, es decir las personas involucradas como partes dentro del proceso. El fundamento de este límite es recogido por el derecho romano, en el que se prescribía que res inter alios iudicata tertio non nocet, es decir la cosa juzgada solo es aplicable con respecto a las partes intervinientes en el proceso ${ }^{58}$. Consecuentemente, la cosa juzgada abarca y engloba solo a aquellos que forman parte de la relación procesal.

A partir de esta premisa, es menester enfocar y detallar los casos que deben ser analizados para poder ejercer una nueva acción civil en busca de la indemnización correspondiente por los daños sufridos. El primer caso es aquel en el cual, como partes procesales, tiene al imputado frente a la Fiscalía General del Estado solamente. Dentro de esta decisión, el juez penal no previó o tasó los daños ocurridos, y existe una cuantificación parcial de daños o simplemente no existió el método de cuantificación de daños.

El segundo caso, es aquel en el cual como partes procesales tienen al imputado frente a la Fiscalía y a la acusación particular que busca la correcta indemnización de perjuicios. Como respuesta obtuvo una cuantificación parcial de daños o simplemente no existió el método de tasación de daños.

Con este nexo, es preciso analizar el caso que compete al estudio de este trabajo, con respecto a la sentencia emitida en sede penal, existen dos posibilidades que tratar: (i) la sentencia en la que la acción penal es ejercida solo por Fiscalía y (ii) la sentencia dictada en contra de la acusación particular.

La primera, como la segunda hipótesis, tienen como partes del proceso penal, por un lado, al victimario o agresor y por el otro a la Fiscalía Genera del Estado como dueña del ejercicio de la acción penal. Mientras que en el nuevo proceso civil se encontrarían la víctima y el victimario. A partir de aquello, se evidencia que en cualquier caso la Fiscalía es el ente encargado de formular o no cargos en contra del imputado, dejando a su arbitrio la capacidad de seguir o no con el proceso, es ahí donde se hace importante el carácter subjetivo de Fiscalía, toda vez que las partes en el proceso penal y nuevo proceso civil son distintas, el agraviado tiene la facultad de acceder a la vía civil para que sus daños sean resarcidos de manera adecuada. A pesar de la existencia de acusación particular, hay que aterrizar en

57 Falcón, Enrique. Op. cit., p. 673

58 Gozaini, Oswaldo. Op. cit., p. 875. 
las capacidades que las partes tienen dentro del proceso. Si Fiscalía no formula cargos, la acusación particular deja de ser tal, ya que el proceso se acaba en ese momento; por tanto, la continuidad del proceso penal con respecto a la acusación particular depende estrictamente de la actuación de Fiscalía.

De este ejemplo práctico, se evidencia la distinción de partes en los diferentes procesos, por lo que cabría un nuevo proceso en el ámbito civil con un enfoque puramente resarcitorio.

Dentro del límite que presenta la cosa juzgada, se encuentran los límites objetivos. Como lo describe Gozaini, este límite es la frontera del fallo judicial para no transponer su eficacia hacia otro proceso donde no existe identidad ${ }^{59}$. El límite objetivo se compone de dos elementos intrínsecos, el objeto o petitum, entiéndase el aspecto material o inmaterial sobre el que las partes buscan determinado interés; y el fundamento del reclamo o causa petendi, cuando estas convergen y estructuran el elemento objetivo se consigue la res in iudicio deductae, elemento esencial para la eficacia de la cosa juzgada ${ }^{60}$.

1. Objeto o petitum. En palabras de Chiovenda, "es la cosa demandada a la cual debe dársele un sentido de lectura amplio, estos pueden ser materiales o inmateriales ${ }^{61}$. Este objeto es la pretensión negada o aceptada en un proceso anterior que se traduce al "bien de la vida" que yace en la sentencia ejecutoriada ${ }^{62}$. En síntesis, el petitum es lo que se busca obtener tras un proceso judicial, es aquello por lo que las partes tienen diferencias. En términos simples, estos podrían ser los hechos alegados y el fin buscado.

2. Fundamento o causa petendi. Según Couture, es el fundamento de la pretensión, que debe ser buscado dentro de la demanda y con un criterio formal amplio que busque una interpretación lógica ${ }^{63}$. En este sentido se puede entender que la causa petendi como el fundamento o la razón de la activación del derecho de acción del demandante.

Tras el respectivo análisis de los elementos internos del límite objetivo, cabe aplicarlo en el caso concreto planteado. En el proceso penal, el objeto o petitum es la sanción del infractor al quebrantar el orden público y las buenas costumbres que se espera de los miembros de la sociedad. Cuando han aceptado la convivencia dentro del contrato social, sin importar los hechos, lo que se busca es la pena por haber violado las reglas y leyes establecidas. Cuando existe acusación particular

59 Id., p. 877.

60 Falcón, Enrique. Óp. cit., p. 686

61 Chiovenda, Giuseppe. Instituciones de Derecho Procesal Civil, Madrid: Editorial Revista de Derecho Privado, 1948, p. 325.

62 Echandía Devis, Hernando. Op. cit., p. 449.

63 Couture, Eduardo. Fundamentos del Derecho Procesal Civil, Buenos Aires: Roque Depa, 1958, p. 318. 
lo que se busca, además de la sanción penal, es que el daño sufrido a causa del delito sea resarcido en legal y debida forma. Por lo que, en primera instancia, no cabría la posibilidad de demandar por vía civil el resarcimiento de daños, siempre y cuando estos hayan sido satisfechos de manera plena.

Hay que establecer de manera clara y concisa que, si la indemnización no corresponde a una compensación total y completa, simplemente la res judicata deja de surtir efectos, debido a que su primordial deber no ha sido cumplido. Por esta razón, la revisión de la cosa juzgada se llevaría a cabo con un resultado positivo frente a la víctima que busca la correcta indemnización por daños.

Con respecto a la causa petendi, el fundamento normativo rompería y fragmentaría la cosa juzgada en todo sentido. Por una parte, en materia penal siempre se está a la expectativa de cumplir la tipificación del código penal, respetando así el principio de legalidad. Por otra parte, en el ámbito civil, lo que se alega sería una infracción al deber general de responsabilidad y cuidado, al que todos los miembros de la sociedad están sujetos como un estándar de conducta deseable por el ordenamiento. En este aspecto no importa cuál fue el hecho fáctico que causa el daño, debido a que, tanto en materia civil como en penal, el análisis será distinto. Por un lado, el primero analizará si el hecho fáctico cumple o no la normativa alegada. Por otro lado, el segundo caso se verificará con la simple vulneración de este deber, por lo que procedería la indemnización a causa de un delito o cuasidelito civil.

Se ha evidenciado y comprobado que la cosa juzgada puede mantener su carácter de inmutabilidad, siempre y cuando la resolución que proteja sea correcta en todos sus límites intrínsecos. En el caso de habar de una mala cuantificación de daños o una ausencia de reparación, sin duda alguna, la acción civil tiene cabida y puede llevarse a cabo.

\section{LA PREJUDICIALIDAD}

Hernando Devis Echandía, sostiene que la prejudicialidad es:

aquella cuestión sustancial autónoma que constituye un necesario antecedente lógico-jurídico de la resolución que debe adoptarse en la sentencia, y que es indispensable resolver previamente por otra sentencia [...], en proceso separado, con valor de cosa juzgada, ante el mismo despacho judicial, o en otro distinto, para que sea posible decidir sobre qué es materia del juicio, sea civil o penal, razón por la cual este debe ser suspendido hasta cuando aquella decisión se produzca (énfasis añadido) ${ }^{64}$.

En el mismo sentido, Falcón la define como aquella situación procesal en la cual la resolución de una causa o proceso está supeditada a la resolución de otra cues- 
tión procesal, porque es necesario un antecedente que sirva de sustento para mantener el equilibrio del ordenamiento y evitar fallos contradictorios ${ }^{65}$.

Esta excepción cobra sentido, cuando existe el antecedente lógico-jurídico descrito por Hernando Devis Echandía y Enrique Falcón respectivamente. Sin embargo, como se analizó con anterioridad en la sección de antecedentes [Supra $\$$ 2], esta ha sido una de las formas más comunes de excepcionares de los abogados al enfrentar juicios en distintas jurisdicciones. Debido al rezago existente a causa del art. 41 del Código de Procedimiento Penal derogado, que catalogaba a la responsabilidad civil y penal como una responsabilidad única. Por lo que la prejudicialidad surtía efectos y tomaba sentido ${ }^{66}$.

Una vez esclarecidas las dudas acerca de la distinción entre estas responsabilidades, es evidente que la excepción de prejudicialidad no procede, a excepción de los casos previstos en la ley, que forman parte de la excepción a la regla general. Ya que en estricto sentido no son iguales las responsabilidades. Por lo que no importaría el fallo contradictorio en diferentes materias, dado que su fundamento y objeto son distintos, utilizando el mismo análisis lógico realizado con respecto a la cosa juzgada.

Apoyando la tesis propuesta, es preciso mencionar la evolución del derecho procesal, con respecto a la supuesta supremacía del derecho penal y procesal penal por sobre la jurisdicción civil. Es evidente que quienes utilizan este pensamiento tienen un razonamiento caduco y fuera de contexto con respecto a la evolución del derecho, en la que la jerarquía de materia no tiene sentido. Por lo tanto, la suspensión de procesos no opera cuando se propone la excepción de prejudicialidad, toda vez que los únicos supuestos posibles son la unidad de jurisdicción y los efectos de la cosa juzgada, que ha sido analizada con anterioridad.

Bajo esta premisa, tras tomar en cuenta la diferencia entra las responsabilidades, la inexistencia de supremacía de materias y los límites de la cosa juzgada, cabe afirmar que la prejudicialidad como excepción no procede. Es decir, en el caso que exista un procedimiento penal iniciado, sin acusación particular, la víctima puede acceder al sistema jurisdiccional civil para que su indemnización sea tratada dentro de esta materia. Sin importar el resultado del proceso penal, debido a su total separación.

\section{OtRa EXCEPCIÓN DENTRO DEL NUEVO PROCESO}

En el ordenamiento jurídico ecuatoriano, tras la publicación del Código Orgánico General de Procesos (en adelante COGEP), se prevé varias excepciones que deben ser saneadas en la audiencia de excepciones previas, cuando el proce-

65 Falcón, Enrique. Óp. cit., p. 546.

66 Código de Procedimiento Penal. Eiusdem, artículo 41. 
dimiento sea de dos audiencias, o en la primera fase de la única audiencia cuando el procedimiento así lo establezca. El art. 153 prescribe que "solo se podrán plantear como excepciones previas las siguientes: 5 . Litispendencia" ${ }^{67}$. Es por esta posibilidad, que la litispendencia debe ser analizada, en caso de que la parte que se encuentra en el proceso penal decida iniciar a la par un proceso civil, en busca de la reparación del daño padecido.

\subsection{LA LITISPENDENCIA}

El momento en que se verifican dos procesos simultáneos, se configura la posibilidad del demandado de utilizar la excepción de pleito pendiente o litis pendencia. Gilberto Martínez, al respecto, manifiesta que cuando se ha iniciado un proceso penal, y existe acusación particular, la facultad se hace imposible, toda vez que ser parte civil dentro de un proceso penal busca como consecuencia una indemnización civil por el daño causado a costa del ilícito ${ }^{68}$. Se comparte totalmente el criterio expuesto por el autor, debido a que la única forma en la que la excepción de pleito pendiente no surta efectos es que el proceso penal siga su curso, sin una acusación particular y, con esta premisa, la víctima busque su indemnización por vía civil.

Vescovi define a esta excepción como aquella que consiste en la defensa que tiene el demandado para no contestar, alegando el hecho de que existe pendiente, ante otro tribunal, la misma demanda ${ }^{69}$. Al respecto, se introduce en el concepto y se manifiesta que es aquella excepción que es dable frente a otro proceso iniciado, sobra la base de los mismos hechos, en los que se tiene que verificar y aplicar los límites de la cosa juzgada.

Debido a que es la única forma en la que se verificaría si en realidad el proceso es el mismo o no. Es decir, el juez, en ejercicio de sus potestades, debe realizar el análisis de carácter, subjetivo (res inter alios iudicata tertio non nocet) y objetivo (petitum y causa petendi), para desechar o dar continuidad al proceso en el que se le alega litis pendencia.

\section{Conclusiones}

A lo largo del presente trabajo se han analizado los principales puntos que se debe tomar en cuenta con respecto a las dudas y puntos claves planteados. De estos se desprende varias conclusiones que efectivamente se han estructurado en el presente documento por secciones para mejor comprensión del lector.

67 Código Orgánico General de Proceso. Artículo 153. Registro Oficial No. 506 Suplemento de 18 de diciembre de 2015. 68 Martínez Rave, Gilberto. Op. cit., p. 97.

69 Vescovi, Enrique. Teoría general del proceso. Bogotá: Temis, 1984, p. 110. 
Dentro de los antecedentes, se puede comprobar el avance que el derecho de responsabilidad por daños ha tenido, respecto a los tipos de responsabilidad analizados, civil y penal. Ya que ha existido un constante cambio dependiendo de la época en la que se lo analice. De la misma manera, cuando se aterrizó en el ordenamiento jurídico ecuatoriano histórico, se evidenció el rezago que las normas de antaño han perpetuado hasta la actualidad.

Esto trae como resultado un pensamiento confuso, al sostener que la responsabilidad civil y la responsabilidad penal son lo mismo. Así, sobre la base de un artículo en el que se exigía la prejudicialidad penal para casos en los que se buscaba una indemnización civil, si el hecho ilícito se encontraba tipificado. La conclusión a que se llega dentro de esta sección es que, a todas luces, existe una distinción entre la responsabilidad civil y penal en el Derecho ecuatoriano. Además, que es incorrecto utilizar una norma anacrónica para estructurar un pensamiento jurídico totalmente equívoco.

Con posterioridad, se analizó las diferentes posturas que existen en la doctrina, respecto de la responsabilidad civil y penal. Así, se reafirma la existencia de varias diferencias entre ellas. También, se concluyó que el concepto de supremacía de la materia penal o su única responsabilidad son anticuados, y no corresponden con la dinámica actual que el Derecho presenta.

De la misma manera, se analizó el principio de reparación integral consagrado en el texto constitucional, que genera una prórroga de competencias del juez penal con respecto a temas indemnizatorios civiles. En este sentido, se concluye que el problema no radica en la extensión de facultades, sino en el mal uso del ejercicio de dichas potestades toda vez que el juez penal no tiene momento procesal alguno en el que se pueda inferir que se realiza una evaluación y posterior tasación de daños. En efecto, la autoridad falla a ciegas y dispone reparaciones sobre la base de su criterio.

A partir de este punto, es importante precisar que el punto central sobre el que recae el documento es la destrucción de la inmutabilidad de las sentencias cobijadas con el carácter de cosa juzgada. Debido al correcto análisis realizado con respecto de los límites subjetivos y objetivos de la res judicata, en que se pudo determinar que existen diferencias notorias con respecto a las partes involucradas, al petitum y su causa petendi.

Sobre la base de este análisis, se pretendió estudiar dos tipos de excepciones a parte de la ya mencionada. Estas son la prejudicialidad y la litispendencia. Es preciso aclarar que estas son el mecanismo de excepciones más comunes cuando se presentan o se evidencian dos procesos distintos en los que puede existir un parecido y el juez es el encargado de ratificar o no esta supuesta similitud. 
En este mismo sentido, se concluye que la institución de la cosa juzgada no es un absoluto, y que puede ser modificada, siempre y cuando se fragmenten sus límites de aplicabilidad, compartiendo el análisis con las excepciones de prejudicialidad y litispendencia. Sin embargo, se ratifica que es deber de los abogados analizar la filigrana jurídica intrínseca de cada institución para realizar un correcto argumento y subsumirlo en el caso concreto.

Finalmente se concluye que los jueces penales, debido a la extensión de sus competencias con respecto a temas indemnizatorios civiles, deberían conocer la forma correcta en la que se debe indemnizar cualquier tipo de daño causado. Además de tener la capacidad de distinguir los daños que el COIP llama materiales e inmateriales, para evitar que las víctimas busquen la vía civil como solución a los problemas planteados. 